\title{
Decreased serum zinc is an effect of ageing and not Alzheimer's disease $\dagger$
}

Cite this: Metallomics, 2014,

6, 1216

Received 5th March 2014,

Accepted 19th March 2014

DOI: $10.1039 / \mathrm{c} 4 \mathrm{mt} 00060 \mathrm{a}$

www.rsc.org/metallomics

\author{
Alan Rembach, $\ddagger^{a}$ Dominic J. Hare $\ddagger^{\text {ab }}$ James D. Doecke, ${ }^{\text {cd }}$ Samantha C. Burnham, ${ }^{c}$ \\ Irene Volitakis, ${ }^{a}$ Christopher J. Fowler, ${ }^{a}$ Robert A. Cherny, ${ }^{a}$ Catriona McLean, \\ Rudolf Grimm, ${ }^{f}$ Ralph Martins, ${ }^{9}$ David Ames, ${ }^{\text {h }}$ Colin L. Masters, ${ }^{a}$ Ashley I. Bush ${ }^{a}$ and \\ Blaine R. Roberts*a
}

We examined the distribution of zinc in the periphery (erythrocytes and serum) in a large, well-characterised cohort, the Australian Imaging, Biomarkers and Lifestyle (AIBL) study, in order to determine if there is systemic perturbation in zinc homeostasis in Alzheimer's disease (AD). We observed an age dependent decrease in serum zinc of approximately $0.4 \%$ per year. When correcting for the age dependent decline in serum zinc no significant difference between healthy controls $(\mathrm{HC})$, mildly cognitively impaired $(\mathrm{MCl})$ or $A D$ subjects was observed.

Alzheimer's disease (AD) is the most prevalent cause of dementia in the aged community, and is a progressive and chronic neurodegeneration that is expected to afflict over 115 million individuals worldwide by 2050 if effective disease modifying treatments are not identified. ${ }^{1} \mathrm{AD}$ is characterised by the accumulation of aggregated amyloid beta $(\mathrm{A} \beta)$ in extracellular plaques and neuronal tangles of phosphorylated tau, ${ }^{2}$ yet despite considerable knowledge concerning the underlying processes in $\mathrm{AD}$, the precise toxic principal of this disorder has yet to be identified.

The concept of a loss of metallostasis, ${ }^{3}$ or a disturbance in metal homeostasis, has recently been proposed as a key element in the pathway leading to $\mathrm{A} \beta$ toxicity and $\mathrm{AD} .^{4-8}$ In particular, zinc has been the focus of intense research for its critical role in

\footnotetext{
${ }^{a}$ The Florey Institute of Neuroscience and Mental Health, The University of Melbourne, Parkville, Victoria, Australia. E-mail: blaine.roberts@florey.edu.au

${ }^{b}$ Elemental Bio-imaging Centre, University of Technology, Sydney, Broadway, New South Wales, Australia

${ }^{c}$ CSIRO Preventative Health Flagship: Mathematics, Informatics and Statistics, Perth, Western Australia, Australia

${ }^{d}$ The Australian e-Health Research Centre, Herston, Queensland, Australia

${ }^{e}$ Anatomical Pathology, The Alfred Hospital, Melbourne, Victoria, Australia

${ }^{f}$ Agilent Technologies, Santa Clara, California, USA

${ }^{g}$ James McCusker Alzheimer's Disease Research Unit,

Health Department of Western Australia, Western Australia, Australia

${ }^{h}$ National Ageing Research Institute, Parkville, Victoria, Australia

$\dagger$ Electronic supplementary information (ESI) available: Supplementary methods, figure, tables and references. See DOI: 10.1039/c4mt00060a

\$ Contributed equally.
}

synaptic maintenance and neuronal transmission. ${ }^{9,10}$ In the brain, zinc is a redox-inert but essential biological metal involved in a range of catalytic activities ${ }^{11}$ and is implicated in $\mathrm{AD}$ for its role in amyloid precursor protein transcription, ${ }^{12-14}$ and in inducing soluble $A \beta$ to aggregate and precipitate. ${ }^{15-18}$ Levels of peripheral zinc have been studied as putative disease biomarkers, though inconsistencies have emerged indicating that serum or plasma zinc may not reflect changes occurring in the central nervous system (CNS). A number of conflicting studies have shown a significant increase, ${ }^{19}$ a significant decrease, ${ }^{20-23}$ or no differences ${ }^{24,25}$ in peripheral zinc in AD when compared to healthy subjects. Furthermore, studies of the zinc concentration in cerebral spinal fluid (CSF) have produced varying results indicating either a decrease in CSF zinc in $\mathrm{AD}^{26}$ or no significant difference from control groups. ${ }^{27,28}$ Even within the $\mathrm{AD}$ brain itself, reported changes to total zinc levels are inconsistent, ${ }^{29,30}$ with decreased zinc reported in certain brain regions, ${ }^{31,32}$ contrasting an increase observed in other areas, ${ }^{33-36}$ These inconsistencies are most likely due to low statistical power from a limited number of samples.

AIBL is a unique resource of over 1000 enrolled AD, MCI and HCs. It is a longitudinal, prospective and multidisciplinary study that compares clinically characterised participants with amyloid imaging modalities, ${ }^{37}$ providing significant power to fully assess peripheral zinc status in a large, well-characterised AD cohort. Thus, the aim of this study was to examine the distribution of zinc in the periphery (erythrocytes and serum) in the AIBL study to determine if there is systemic perturbation in zinc homeostasis measurable in blood.

Serum zinc concentration was measured in the baseline AIBL cohort of 1084 subjects (complete, less 28 samples of the total 1112, which were deemed unsuitable for analysis). Comprehensive demographics, including age, sex, apolipoprotein-E type 4 (ApoE\&4) allele status, Clinical Dementia Rating Scale Sum of Boxes score (CDR SOB; used to stage dementia) and mini-mental state examination (MMSE) questionnaire score are presented in Table 1. In the AIBL cohort, the HC group are significantly younger than the $\mathrm{AD}$ group $(p<0.0001)$, and contain a smaller 
Table 1 Serum zinc cohort demographics. ApoE\&4 refers to the number of subjects with at least 1 apolipoprotein $\& 4$ allele. CDR SOB is the Clinical Dementia Rating Scale Sum of Boxes score used to stage dementia. MMSE is the mini-mental state examination questionnaire score. Figures in parentheses are 1 standard deviation

\begin{tabular}{lllll}
\hline Classification & HC & MCI & AD & $p$-value \\
\hline$N$ & 753 & 126 & 205 & \\
Age, years & $70.6(7)$ & $76.2(7.6)$ & $78.8(8.6)$ & $<0.001$ \\
Sex, $n$ female & 434 & 72 & 127 & 0.335 \\
ApoE 4 & 205 & 63 & 128 & $<0.001$ \\
CDR SOB & $0.0(0.1)$ & $1.2(0.8)$ & $5.8(2.9)$ & $<0.001$ \\
MMSE & $28.9(1.2)$ & $26.2(2.7)$ & $18.9(5.3)$ & $<0.001$ \\
\hline
\end{tabular}

number of ApoE\&4 carriers ( $p<0.0001)$. As expected, CDR SOB and MMSE score are consistently and significantly lower in the AD cohort $(p<0.0001)$. There was no difference in the proportion of males to females between the clinical classification groups $(p=0.335)$.

Analytical validity of our ICP-MS zinc assay was tested against a commercial standard serum (Seronorm ${ }^{\mathrm{TM}}$ ) and spike recovery from a characterised serum standard (Table S1, ESI $\dagger$ ). 1084 individual serum samples were analysed over a 6-day period. Recovery of zinc from Seronorm ${ }^{\mathrm{TM}}$ standards was measured twice daily and was consistently within $10 \%$ of certified values. Similarly, spiked serum displayed good precision and accuracy in daily quality control checks. Twenty-five individual calibrations were performed, with acceptable background equivalent concentration $\left(0.892 \pm 0.65 \mu \mathrm{g} \mathrm{L}^{-1}\right)$ and detection limits $\left.(0.511 \pm 0.871 \mu \mathrm{g} \mathrm{L})^{-1}\right)$ and linearity $\left(R^{2}>0.999\right)$ over the analysis period.

Serum zinc concentrations were subdivided according to clinical classification, sex and ApoE\&4 allele distribution (Table 2). There was a subtle decrease in zinc concentration in $\mathrm{AD}$ subjects when compared to HCs (HC $12.730 \pm 2.489 \mu \mathrm{M} v s$. $\mathrm{AD} 12.206 \pm 2.808 \mu \mathrm{M}$ ). ANOVA of the marginal means across all three clinical groups showed a significant decrease in serum zinc levels $(p=0.003)$. Comparisons showed that this difference was driven by the HC $v s$. AD group difference $(p=0.001)$, with the HC-MCI group comparison not significantly different $(p=0.679)$.

Independent of clinical classification we observed a small but significant decrease in serum zinc with age (Fig. 1a; see Fig. S1 (ESI $\dagger$ ) for serum zinc levels in each classification), equating to a $0.051 \pm 0.042 \mu \mathrm{M}$ per year decrease in the AIBL cohort, or $0.40 \pm 0.33 \%$ per year of mean serum zinc concentration. In AIBL, where $\mathrm{AD}$ subjects are, on average, 8.2 years older than their a)

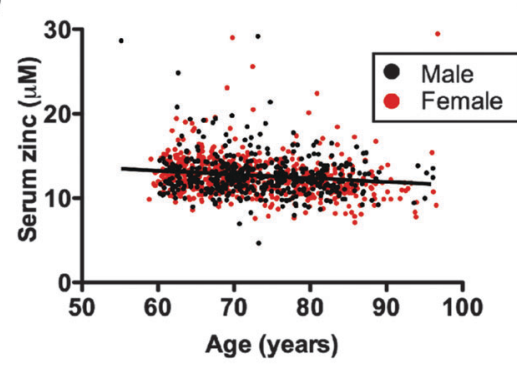

b)

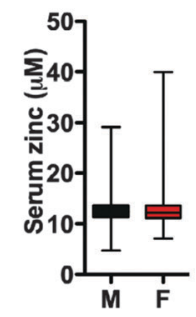

c)
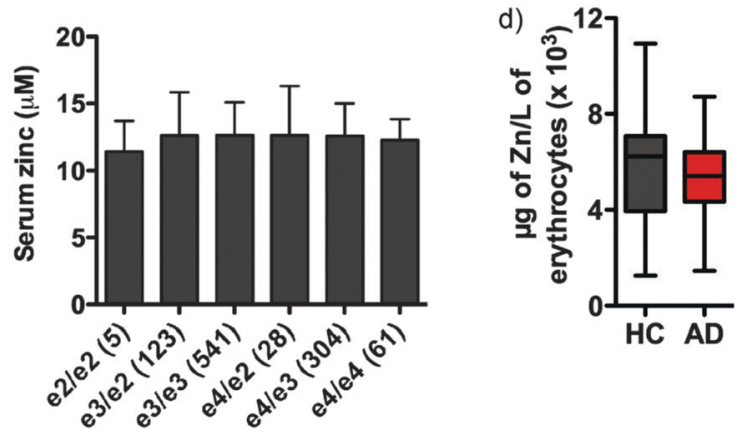

Fig. 1 (a) Serum zinc decreases with age and is (b) consistent between sex, (c) ApoE allele status ( $n$ in parentheses) and (d) not significantly different in the erythrocyte fraction between $H C$ and $A D$.

HC counterparts, this decrease in serum zinc with age represents a $0.418 \pm 0.344 \mu \mathrm{M}$ disparity between the two cohorts, which likely accounts for the $0.524 \mu \mathrm{M}$ difference in serum zinc observed. Thus, when correcting for age as a covariate in the AIBL population, ${ }^{38}$ the previously observed decrease in serum zinc was abolished.

Unlike previous reports, ${ }^{39}$ we did not observe a significant difference in serum zinc concentration according to sex (Fig. 1b). Serum zinc levels did appear lower in AD females as compared with $\mathrm{AD}$ males, however this did not reach statistical significance (female AD $11.910 \pm 2.413 \mu \mathrm{M}$ vs. male AD $12.706 \pm 3.332 \mu \mathrm{M}$; $p=0.073)$. ANOVA of serum zinc levels according to ApoE allele status was also unchanged (Fig. 1c). As ApoE\&4 carriers have increased risk of developing $\mathrm{AD},{ }^{40}$ we also examined the influence of $A p o E$ allele status in each clinical classification. No statistically significant difference was observed between classes or within each classification (Table S2, ESI $\dagger$ ), though there was a decreasing trend in ApoE\&4 carriers across the three clinical classifications. Similarly, in a pilot study AD and HC participants ( $n=40$ per group) showed no significant difference in erythrocyte zinc concentration (Fig. 1d).

Table 2 Serum zinc concentration by classification, sex and $A p \circ E \varepsilon 4$ allele status, and significance before and after correction for age, sex and ApoE 4 status. Figures in parentheses are 1 standard deviation. Adjusted $p$-value represents significance after correction for age as a type I error

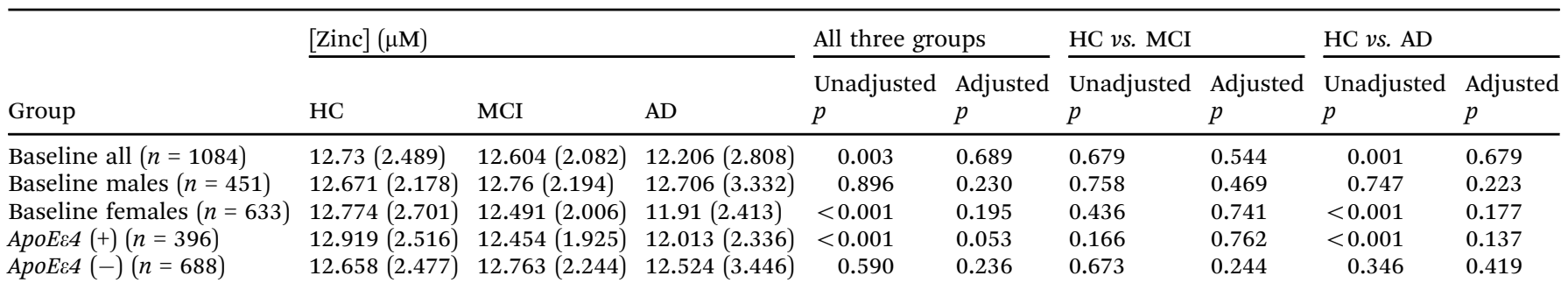


a)

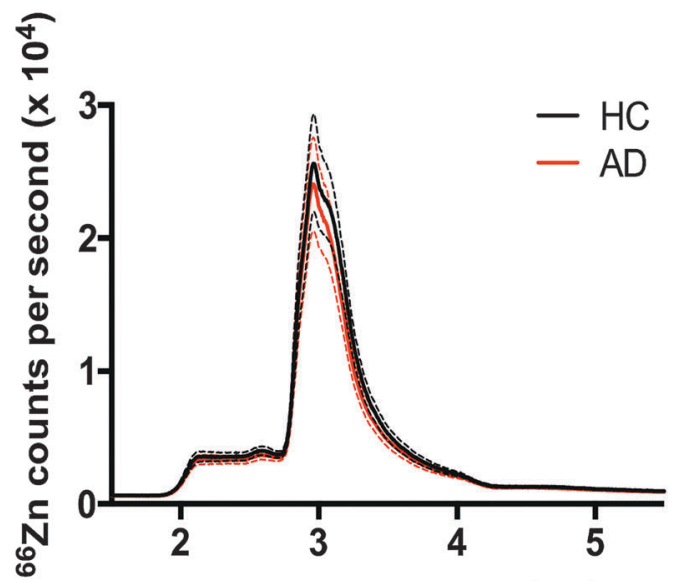

b)

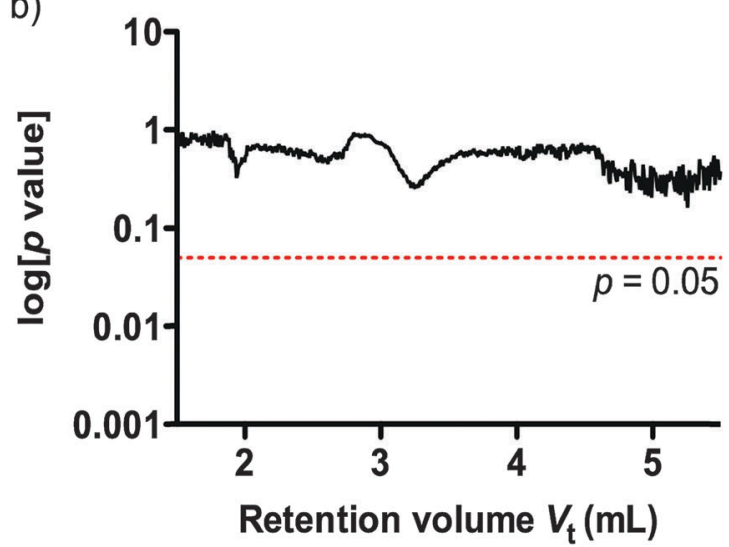

Fig. 2 (a) SEC-ICP-MS chromatograms of mean ${ }^{66} \mathrm{Zn}$ signal (solid line, $\pm 1 \mathrm{SD}$ dashed lines) in $38 \mathrm{AD}$ and $38 \mathrm{HC}$ subjects. (b) A two-tailed $t$-test on each point revealed no significant difference between groups.

Understanding that subtle changes in serum zinc may not be reflected in bulk analysis, we used size exclusion inductively coupled plasma mass spectrometry (SEC-ICP-MS ${ }^{41}$ to profile the zinc binding species present in plasma according to molecular size of protein species. Using SEC-ICP-MS we compared the zinc profile of $38 \mathrm{HC}$ and $38 \mathrm{AD}$ age and sex matched subjects. Reflecting the total serum zinc results, we observed no significant difference in zinc levels attributable to zinc-binding proteins in either clinical group (Fig. 2) ( $p>0.05)$.

Peripheral zinc levels are highly regulated and are under the influence of homeostatic and environmental parameters such as diet or the concentration of other metals, including copper, and it is assumed that zinc homeostasis is compromised during the aging processes. In $\mathrm{AIBL}$, the $\mathrm{Cu} / \mathrm{Zn}$ ratio was slightly higher in the $\mathrm{AD}$ cohort $(\mathrm{HC}=0.824 ; \mathrm{MCI}=0.806 ; \mathrm{AD}=0.798 ; p=0.085)$ though again this was attributed to effects of age, as has been shown by others. ${ }^{42}$

We propose that previously reported decreases in serum zinc concentration may be attributed to either small data sets with low statistical power, ${ }^{20,21}$ or an effect of decreased zinc in the typically older AD population. ${ }^{22,23}$ The size of the AIBL study permits detailed study into the effects of age on serum zinc levels, which we found decreases inline with age. This does not, however, suggest that zinc is not implicated in AD pathology in the brain, where zinc enrichment in amyloid pathology is a robust feature of the disease. ${ }^{29,30,43}$ Regardless, we conclude that it is unlikely variations in zinc concentration due to changes in CNS metallostasis in $\mathrm{AD}$ can be detected in the periphery without the covariate influence of ageing masking subtle changes that are independent of disease.

\section{Acknowledgements}

We wish to thank the Australian Imaging, Biomarkers and Lifestyle Flagship Study of Ageing (http://www.aibl.csiro.au/), including all scientists, participants and their families. This work was supported by the Cooperative Research Centre for Mental Health and by Operational Infrastructure Support from the Victorian State Government.

\section{Notes and references}

1 Alzheimer's Association, Alzheimer's Dementia, 2012, 8, 131-168.

2 C. Haass and D. J. Selkoe, Nat. Rev. Mol. Cell Biol., 2007, 8, 101-112.

3 S. Ayton, P. Lei and A. I. Bush, Free Radical Biol. Med., 2013, 62, 76-89.

4 X. Huang, R. D. Moir, R. E. Tanzi, A. I. Bush and J. T. Rogers, Ann. N. Y. Acad. Sci., 2004, 1012, 153-163.

5 R. Squitti, Front. Biosci., 2012, 17, 451-472.

6 B. R. Roberts, T. M. Ryan, A. I. Bush, C. L. Masters and J. A. Duce, J. Neurochem., 2012, 120(suppl 1), 149-166.

7 I. Shcherbatykh and D. O. Carpenter, J. Alzheimer's Dis., 2007, 11, 191-205.

8 A. I. Bush, J. Alzheimer's Dis., 2013, 33(suppl 1), S277-S281.

9 G. J. Brewer, BioFactors, 2012, 38, 107-113.

10 G. Lyubartseva and M. A. Lovell, BioFactors, 2012, 38, 98-106.

11 C. J. Frederickson, M. D. Hernandez and J. F. McGinty, Brain Res., 1989, 480, 317-321.

12 D. Bittel, T. Dalton, S. L. Samson, L. Gedamu and G. K. Andrews, J. Biol. Chem., 1998, 273, 7127-7133.

13 T. P. Dalton, D. Bittel and G. K. Andrews, Mol. Cell. Biol., 1997, 17, 2781-2789.

14 T. P. Dalton, Q. Li, D. Bittel, L. Liang and G. K. Andrews, J. Biol. Chem., 1996, 271, 26233-26241.

15 A. Bush, W. Pettingell, G. Multhaup, M. d Paradis, J. Vonsattel, J. Gusella, K. Beyreuther, C. Masters and R. Tanzi, Science, 1994, 265, 1464-1467.

16 X. Huang, C. S. Atwood, M. A. Hartshorn, G. Multhaup, L. E. Goldstein, R. C. Scarpa, M. P. Cuajungco, D. N. Gray, J. Lim, R. D. Moir, R. E. Tanzi and A. I. Bush, Biochemistry, 1999, 38, 7609-7616.

17 X. Huang, C. S. Atwood, R. D. Moir, M. A. Hartshorn, J. P. Vonsattel, R. E. Tanzi and A. I. Bush, J. Biol. Chem., 1997, 272, 26464-26470.

18 Y. Miller, B. Ma and R. Nussinov, Proc. Natl. Acad. Sci. U. S. A., 2010, 107, 9490-9495. 
19 C. Gonzalez, T. Martin, J. Cacho, M. T. Brenas, T. Arroyo, B. Garcia-Berrocal, J. A. Navajo and J. M. Gonzalez-Buitrago, Eur. J. Clin. Invest., 1999, 29, 637-642.

20 C. Jeandel, M. B. Nicolas, F. Dubois, F. Nabet-Belleville, F. Penin and G. Cuny, Gerontology, 1989, 35, 275-282.

21 L. Baum, I. H. S. Chan, S. K. K. Cheung, W. B. Goggins, V. Mok, L. Lam, V. Leung, E. Hui, C. Ng and J. Woo, BioMetals, 2010, 23, 173-179.

22 G. J. Brewer, S. H. Kanzer, E. A. Zimmerman, E. S. Molho, D. F. Celmins, S. M. Heckman and R. Dick, Am. J. Alzheimers Dis. Other Demen., 2010, 25, 572-575.

23 H. Vural, H. Demirin, Y. Kara, I. Eren and N. Delibas, J. Trace Elem. Med. Biol., 2010, 24, 169-173.

24 D. Shore, R. I. Henkin, N. R. Nelson, R. P. Agarwal and R. J. Wyatt, J. Am. Geriatr. Soc., 1984, 32, 892-895.

25 A. Haines, S. Iliffe, P. Morgan, T. Dormandy and B. Wood, Clin. Chim. Acta, 1991, 198, 261-266.

26 J. A. Molina, F. J. Jimenez-Jimenez, M. V. Aguilar, I. Meseguer, C. J. Mateos-Vega, M. J. Gonzalez-Munoz, F. de Bustos, J. Porta, M. Orti-Pareja, M. Zurdo, E. Barrios and M. C. Martinez-Para, J. Neural Transm.: Gen. Sect., 1998, 105, 479-488.

27 C. O. Hershey, L. A. Hershey, A. Varnes, S. D. Vibhakar, P. Lavin and W. H. Strain, Neurology, 1983, 33, 1350-1353.

28 R. N. Sahu, R. S. Pandey, M. N. Subhash, B. Y. Arya, T. S. Padmashree and K. N. Srinivas, Biol. Psychiatry, 1988, 24, 480-482.

29 J. R. Nuttall and P. I. Oteiza, Genes Nutr., 2014, 9, 379.

30 M. A. Lovell, J. D. Robertson, W. J. Teesdale, J. L. Campbell and W. R. Markesbery, J. Neurol. Sci., 1998, 158, 47-52.

31 F. M. Corrigan, G. P. Reynolds and N. I. Ward, BioMetals, 1993, 6, 149-154.
32 A. E. Panayi, N. M. Spyrou, B. S. Iversen, M. A. White and P. Part, J. Neurol. Sci., 2002, 195, 1-10.

33 G. Danscher, K. B. Jensen, C. J. Frederickson, K. Kemp, A. Andreasen, S. Juhl, M. Stoltenberg and R. Ravid, J. Neurosci. Methods, 1997, 76, 53-59.

34 D. Religa, D. Strozyk, R. A. Cherny, I. Volitakis, V. Haroutunian, B. Winblad, J. Naslund and A. I. Bush, Neurology, 2006, 67, 69-75.

35 D. L. Samudralwar, C. C. Diprete, B. F. Ni, W. D. Ehmann and W. R. Markesbery, J. Neurol. Sci., 1995, 130, 139-145.

36 C. M. Thompson, W. R. Markesbery, W. D. Ehmann, Y. X. Mao and D. E. Vance, Neurotoxicology, 1988, 9, 1-7.

37 K. A. Ellis, A. I. Bush, D. Darby, D. De Fazio, J. Foster, P. Hudson, N. T. Lautenschlager, N. Lenzo, R. N. Martins, P. Maruff, C. Masters, A. Milner, K. Pike, C. Rowe, G. Savage, C. Szoeke, K. Taddei, V. Villemagne, M. Woodward, D. Ames and A. R. Group, Int. Psychogeriatr., 2009, 21, 672-687.

38 Y. Hochberg and Y. Benjamini, Stat. Med., 1990, 9, 811-818. 39 I. M. Rea, Nutr. Res., 1989, 9, 121-125.

40 E. Corder, A. Saunders, W. Strittmatter, D. Schmechel, P. Gaskell, G. Small, A. Roses, J. Haines and M. PericakVance, Science, 1993, 261, 921-923.

41 D. J. Hare, A. Grubman, T. M. Ryan, A. Lothian, J. R. Liddell, R. Grimm, T. Matsuda, P. A. Doble, R. A. Cherny, A. I. Bush, A. R. White, C. L. Masters and B. R. Roberts, Metallomics, 2013, 5, 1656-1662.

42 A. Mezzetti, S. D. Pierdomenico, F. Costantini, F. Romano, D. De Cesare, F. Cuccurullo, T. Imbastaro, G. Riario-Sforza, F. Di Giacomo, G. Zuliani and R. Fellin, Free Radical Biol. Med., 1998, 25, 676-681.

43 L. M. Miller, Q. Wang, T. P. Telivala, R. J. Smith, A. Lanzirotti and J. Miklossy, J. Struct. Biol., 2006, 155, 30-37. 